\title{
There Might be a Risk of Anaphylaxis Due to Omalizumab (Anti-IgE) Therapy
}

\author{
Yalcin $\mathrm{AD}^{1 *}$, Suer $\mathrm{K}^{2}$ and Yalcin $\mathbf{A N}^{3}$
}

${ }^{1}$ Near East University, Nicosia, Cyprus and Genomics Research Center, Internal Medicine, Allergy and Clinical Immunology, Academia Sinica, 11529, Taipei, Taiwan

${ }^{2}$ Department of Infectious Diseases and Clinical Microbiology, Near East University, Nicosia, Cyprus

${ }^{3}$ Department of Infectious Diseases and Clinical Microbiology, Akdeniz University, Medicine Faculty, Antalya, Turkey

Received: September 10, 2014; Accepted: October 28, 2014; Published: November 13, 2014

*Corresponding author: Arzu Didem Yalcin, Near East University, Nicosia, Cyprus and Genomics Research Center, Internal Medicine, Allergy and Clinical Immunology, Academia Sinica, 11529, Taipei, Taiwan, Tel: +8860-278977509; E-mail: adidyal@gate.sinica.edu.tw

\begin{abstract}
Omalizumab, a humanized mAb that binds to the $\mathrm{CH} 3$ domain, near the binding site for the high-affinity type-I IgE Fc receptors of human IgE, can neutralize free IgE and inhibit the IgE allergic pathway without sensitizing mast cell and basophils. The clinical experience during the patient follow-up of an omalizumab treated severe persistent allergic asthma patient with complicated viral infection is introduced.
\end{abstract}

A female patient (aged 58) with severe persistent allergic asthma, on omalizumab therapy had laryngeal oedema during a complicated common cold infection with bacterial sinusitis after omalizumab injection. Systemic steroids, ketotifen fumarate, antibiotic and antihistamines (desloratadine) were given. We did not stop omalizumab therapy. To our knowledge, this is the first time an association between omalizumab use and laryngeal oedema has been documented. In fact we do not know the exact mechanism behind this relationship.

In conclusion we do not suggest Omalizumab during the first five days of complicated viral infections such as common cold and bacterial sinus infections.

Keywords: Asthma; Anti-IgE; Omalizumab; Anaphylaxis; Side effect; Safety; Allergic asthma; Severe persistent allergic asthma; Fever; Common cold; Viral infections; Laryngeal oedema; Pulse steroid; Bacterial sinus infections; Desloratadine; Ketotifen fumarate

\section{Introduction}

Omalizumab, a humanized mAb that binds to the $\mathrm{CH} 3$ domain, near the binding site for the high-affinity type-I IgE Fc receptors of human IgE, can neutralize free IgE and inhibit the IgE allergic pathway without sensitizing mast cell and basophils. Omalizumab is a humanized recombinant anti-IgE monoclonal antibody approved for therapeutic use both in adults and in children aged 6-12 years with severe allergic asthma. The coexistence of severe asthma refractory to the conventional pharmacological approach and sensitization to at least one perennial allergen represent the current indications for Omalizumab prescription. Its efficacy and safety as an add-on therapy is sustained by several data coming from both clinical trials and real-life experiences [1-10] and showing a significant reduction of yearly exacerbation-rate.
The most common adverse reaction from omalizumab is injection site in duration, injection site itching, injection site pain and bruising but the package insert contains warnings regarding parasitic infections. While there are no reports of fatal anaphylaxis as a result of omalizumab, some cases have been serious and potentially life-threatening. Therefore, the FDA requires that people receiving omalizumab be monitored in the physician's office for a period of time after their injections.

A female patient with severe persistent allergic asthma, aged 58 is introduced. Laboratory tests are below; Anti Nuclear Antibody, and hepatitis markers (HBsAg, HBsAb, Anti HCV HIV, thyroid antibodies were negative, autologous serum skin test were positive. Liver, thyroid, and renal function tests, serum IgG, IgA, IgM, levels were within normal ranges. Skin prick tests (SPTs) were highly positive for mite and mold. The specific IgE levels were correlated with the SPTs. Total IgE level were 480 IU/L. Body temperature was $38.5^{\circ} \mathrm{C}$.

The patient had not previously reported drug induced anaphylaxis. On omalizumab (on the $23^{\text {rd }}$ dose) therapy, this patient had laryngeal oedema during a complicated common cold infection with bacterial sinusitis after omalizumab injection.

Systemic steroids (500 mg prednisolone), ketotifen fumarate (1X1), antibiotic and antihistamines (desloratadine, 1X1) were given. Oral antihistaminics and mast cell stabilizing agens used for treatment afterwards. We did not stop omalizumab therapy. We do not suggest omalizumab during the first five days of complicated viral infections such as common cold and bacterial sinus infections.

In conventional thinking the involvement of $\operatorname{IgE}$ in mast cell activation requires the cross-linking of FceRI-bound IgE by antigen or anti-IgE antibodies. In a transcriptome analysis of 8793 genes, sensitization of mast cells with monoclonal IgE alone was found to up regulate 58 genes more than 2 -fold compared with their levels in un-sensitized mast cells. These genes included those for cytokines (IL-1 $\beta$, IL-6, and colony-stimulating factor 1); chemokines (CXCL8, CCL7, CCL4); and chemokine receptors [1113]. Omalizumab, which has been conceptualized for treating IgE 
mediated allergic diseases and approved for treating patients with severe persistent allergic asthma in many countries, can neutralize IgE, impede the IgE allergic pathway, and render mast cells and basophils insensitive activation through IgE/FceRI In addition to asthma, omalizumab has been investigated in various other conditions including chronic urticaria, perennial and seasonal allergic rhinitis, pruritic bullous pemphigoid, latex allergy, peanut allergy, idiopathic anaphylaxis, hyper-IgE syndrome, chronic rhinosinusitis, interstitial cystitis, aspirin sensitivity, mastocytosis, eosinophilic gastroenteritis and atopic dermatitis [14-21].

Rhinoviruses, which are the most common cause of virally induced asthma exacerbations, account for much of the burden of asthma in terms of morbidity, mortality, and associated cost Asthmatic epithelial cells have an increased intrinsic capacity for expression of a pro-type 2 cytokine in response to a viral infection, and IL-25 is a key mediator of asthma exacerbations of pulmonary inflammation [22-25]. To our knowledge, this is the first time, an association between omalizumab use and laryngeal oedema has been documented. Although we do not know the exact mechanism behind this relationship.

\section{Conclusion}

To the best of our knowledge, this is the first case. We do not suggest omalizumab during the first five days of complicated viral infections and bacterial sinus infections. We also believe that complicated viral infections may also have an important role in laryngeal oedema. Further studies are needed to investigate. The prescribing information might have been revised based on post marketing surveillance data and reported such cases indicating that different side effects may occur beyond 2 hours after the injection.

\section{References}

1. Normansell R, Walker S, Milan SJ, Walters EH, Nair P. Omalizumab for asthma in adults and children. Cochrane Database Syst Rev. 2014; doi:10.1002/14651858.CD003559.

2. Vignola AM, Humbert M, Bousquet J, Boulet LP, Hedgecock S, Blogg $\mathrm{M}$, et al. Efficacy and tolerability of anti-immunoglobulin E therapy with omalizumab in patients with concomitant asthma and persistent allergic rhinitis: SOLAR. Allergy. 2004; 59(7):709-717.

3. Humbert M, Beasley R, Ayres J, Slavin R, Hébert J, Bousquet J, et al Benefits of omalizumab as add-on therapy in patients with severe persistent asthma who are inadequately controlled despite best available therapy (GINA 2002 step 4 treatment): INNOVATE. Allergy. 2005; 60(3): 309-316.

4. Hanania NA, Alpan O, Hamilos DL, Condemi JJ, Reyes-Rivera I, Zhu J, et al. Omalizumab in severe allergic asthma inadequately controlled with standard therapy: a randomized trial. Ann Intern Med. 2011; 154(9): 573-582. doi: 10.7326/0003-4819-154-9-201105030-00002.

5. Molimard M, de Blay F, Didier A, Le Gros V. Effectiveness of omalizumab (Xolair) in the first patients treated in real-life practice in France. Respir Med. 2008; 102(1): 71-76.

6. Korn S, Thielen A, Seyfried S, Taube C, Kornmann O, Buhl R. Omalizumab in patients with severe persistent allergic asthma in a real-life setting in Germany. Respir Med. 2009; 103(11): 1725-1731. doi: 10.1016/j.rmed.2009.05.002.
7. Brusselle G, Michils A, Louis R, Dupont L, Van de Maele B, Delobbe A, et al. "Real-life" effectiveness of omalizumab in patients with severe persistent allergic asthma: The PERSIST study. Respir Med. 2009; 103(11): 1633-1642. doi: 10.1016/j.rmed.2009.06.014.

8. Cazzola M, Camiciottoli G, Bonavia M, Gulotta C, Ravazzi A, Alessandrini A, et al. Italian real-life experience of omalizumab. Respir Med. 2010; 104(10): 1410-1416. doi: 10.1016/j.rmed.2010.04.013.

9. Tzortzaki EG, Georgiou A, Kampas D, Lemessios M, Markatos M, Adamidi T, et al. Long-term omalizumab treatment in severe allergic asthma: the South-Eastern Mediterranean "real-life" experience. Pulm Pharmacol Ther. 2012; 25(1): 77-82. doi: 10.1016/j.pupt.2011.11.004.

10.Vennera Mdel C, Pérez De Llano L, Bardagí S, Ausin P, Sanjuas C, González $\mathrm{H}$, et al. Omalizumab therapy in severe asthma: experience from the Spanish registry-some new approaches. J Asthma. 2012; 49(4):416-422. doi: 10.3109/02770903.2012.668255.

11. Asai K, Kitaura J, Kawakami Y, Yamagata N, Tsai M, Carbone DP, et al. Regulation of mast cell survival by IgE. Immunity. 2001; 14(6): 791800 .

12. Kalesnikoff J, Huber M, Lam V, Damen JE, Zhang J, Siraganian RP, et al. Monomeric IgE stimulates signaling pathways in mast cells that lead to cytokine production and cell survival. Immunity. 2001; 14: 801811.

13. Jayapal M, Tay HK, Reghunathan R, Zhi L, Chow KK, Rauff M, et al. Genomewide gene expression profiling of human mast cells stimulated by IgE or FcepsilonRI-aggregation reveals a complex network of genes involved in inflammatory responses. BMC Genomics. 2006; 7: 210.

14. Yalcin AD, Bisgin A, Gorczynski RM. IL-8, IL10, TGF- $\beta$ and GCSF levels were increased in severe persistent allergic asthma patients with the anti-IgE treatment. Mediators Inflamm. 2012; 2012: 720976. doi: 10.1155/2012/720976.

15. Yalcin AD1, Cilli A, Bisgin A, Strauss LG, Herth F. Omalizumab is effective in treating severe asthma in patients with severe cadiovascular complications and its effects on sCD200, d-dimer , CXCL8 and IL-1 $\beta$ levels. Expert Opin Biol Ther. 2013; 13(9): 1335-1341. doi:10.1517/1 4712598.2013.819338.

16. Yalcin AD, Celik B, Gumuslu S. D-dimer levels decreased in severe allergic asthma and chronic urticaria patients with the omalizumab treatment. Expert Opin Biol Ther. 2014 Mar; 14(3): 283-286. doi: 10.1517/14712598.2014.875525.

17. Yalcin AD, Bisgin A, Cetinkaya R, Yildirim M, Gorczynski RM. Clinical Course and Side Effects of Omalizumab in Patients with Severe Persistent Asthma. Clin. Lab. 2013; 59(1-2): 71-77.

18. Yalcin AD, Uçar S, Gumuslu S, Strauss LG. Effects of Omalizumab on Eosinophil Cationic Peptid, 25-Hydroxyvitamin-D, IL-1â, and sCD200 in a cases of Samter's syndrome: 36 Months follow-up. Immunopharmacology And Immunotoxicology. 2013; 35(4): 524527. doi:10.3109/08923973.213.811598.

19. Yalcin AD, Bisgin A. Anti-IgE Therapy in Severe Allergic Conditions. Journal of Allergy and Therapy. 2012; 3:120 doi:10.4172/21556121.1000120 .

20. Yalcin AD. An overview of the effects of Anti-IgE Therapies. Med Sci Monit. 2014; 20: 1691-1699. doi: 10.12659/MSM.890137.

21. Eisner MD, Zazzali JL, Miller MK, Bradley MS, Schatz M. Longitudinal changes in asthma control with omalizumab: 2-year interim data from the EXCELS Study. J Asthma. 2012; 49(6): 642-648. doi: 10.3109/02770903.2012.690477. 
22. Beale J, Jayaraman A, Jackson DJ, Macintyre JD, Edwards MR, Walton $\mathrm{RP}$, et al. Rhinovirus-induced IL-25 in asthma exacerbation drives type 2 immunity and allergic pulmonary inflammation. Sci Trans Med. 2014; 6(256): 256ra134. doi: 10.1126/scitranslmed.3009124.

23. Andreakos E, Papadopoulos NG. IL-25: The Missing Link Between Allergy, Viral Infection, and Asthma? Sci Transl Med. 2014; 6(256): 256fs38. doi: 10.1126/scitranslmed.3010273.
24. Costa LD, Costa PS, Camargos PA. Exacerbation of asthma and airway infection: is the virus the villain?J Pediatr (Rio J). 2014; pii: S0021-7557(14)00123-5. doi: 10.1016/j.jped.2014.07.001.

25. Teeratakulpisarn J, Pientong C, Ekalaksananan T, Ruangsiripiyakul H, Uppala R. Rhinovirus infection in children hospitalized with acute bronchiolitis and its impact on subsequent wheezing or asthma: a comparison of etiologies. Asian Pac J Allergy Immunol. 2014; 32(3): 226-234. doi: 10.12932/AP0417.32.3.2014. 